\title{
Simulation and control of FLC converters for UPS systems
}

\author{
Jiří Brychcín \\ Regional Innovation Centre for Electrical \\ Engineering (RICE) \\ University of West Bohemia \\ Pilsen, Czech Republic \\ brychj@rice.zcu.cz \\ Tomáš Košan \\ Regional Innovation Centre for Electrical \\ Engineering (RICE) \\ University of West Bohemia \\ Pilsen, Czech Republic \\ kosan@rice.zcu.cz
}

\begin{abstract}
This paper is focused on simulation of the diesel or gas electric central, which is used for uninterruptible power supply (UPS) with permanent magnet synchronous generator (PMSG) and flying capacitor converters (FLC).
\end{abstract}

Keywords-UPS; PMSG; FLC; multilevel; modulator; balancing; control; PWM

\section{INTRODUCTION}

This paper presents the simulation of the UPS system with PMSG and FLC converter. Its control technique together with modulation for grid mode and island mode operation and the transition between those two operation modes is also presented. The synchronization technique with and without phase locked loop (PLL) is considered. Finally, the principal of the FLC converter modulation with the active balancing is described in detail and experimentally verified

\section{THE TOPOLOGY}

The topology of this UPS system is shown on Figure 1. The topology is composed of the engine gas or diesel, which is the source of the mechanic torque for the PMSG. The T represents a turbine of the gas engine. This turbine is controlled on the demanded speed through the speed controller. At the output of the speed controller, there is demanded value of the torque of the PMSG. The output of the PMSG is connected through the vector controlled FLC rectifier with DC-link to the vector controlled FLC inverter.

\author{
Dušan Janík \\ Regional Innovation Centre for Electrical \\ Engineering (RICE) \\ University of West Bohemia \\ Pilsen, Czech Republic \\ djanik@rice.zcu.cz \\ Zdeněk Peroutka \\ Regional Innovation Centre for Electrical \\ Engineering (RICE) \\ University of West Bohemia \\ Pilsen, Czech Republic \\ peroutka@ieee.org
}

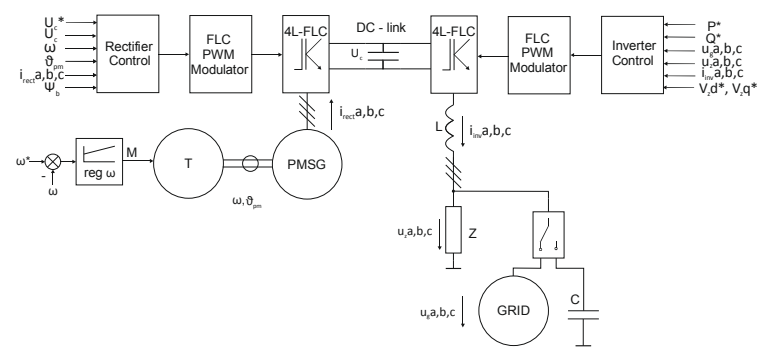

Figure 1 The topology of the UPS system

\section{VECTOR CONTROLLED RECTIFIER}

The power circuit of the FLC converter with the equivalent circuit of the PMSG is shown on Figure 2. The power circuit of the FLC inverter is displayed on the Figure 3. In the Figure 4 there is shown the equivalent circuit and the phasor diagram of PMSG.

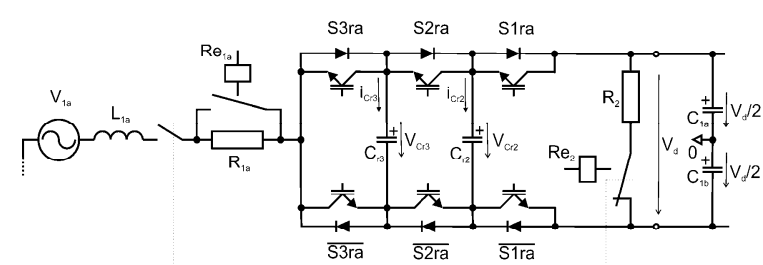

Figure 2 Power circuit of the FLC rectifier with equivalent circuit of the PMSG

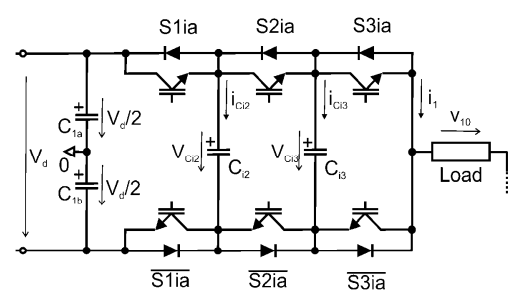

Figure 3 Power circuit of the FLC inverter 


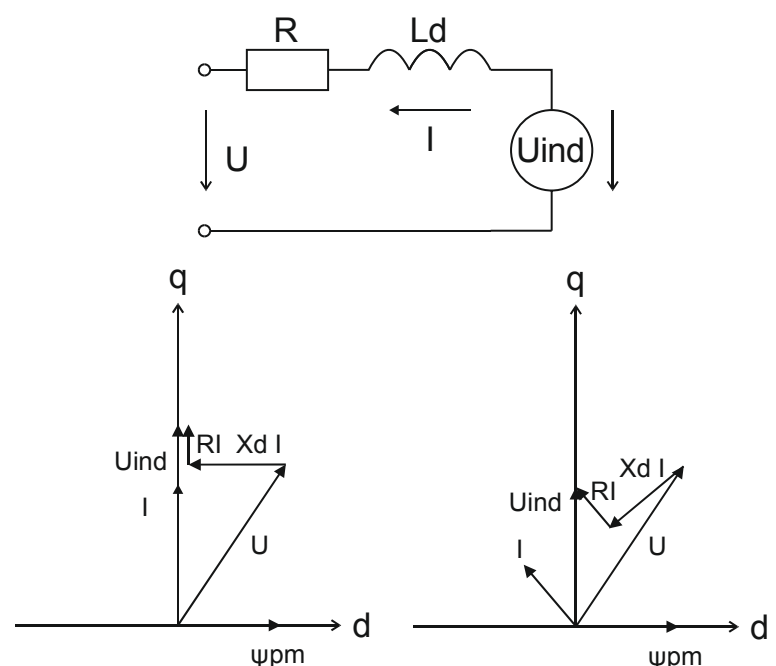

Figure 4 Equivalent circuit of PMSG with phasor diagram

We have used conventional vector oriented control [1]. The structure of the control of presented system with PMSG connected to active rectifier is shown on Figure 5. The main function of the rectifier is to control the voltage of the DC bus. The voltage controller sets the demanded current on its output in $\mathrm{q}$ axe of the dq coordinated system, which influences the torque of the PMSG. The $d$ current component has influence on exciting of the PMSG, it means that, if we set the demanded current in the $d$ axis to zero, then the PMSG will have the full exciting. The id and iq controllers ensure the control of current in the dq coordinated system. The outputs of the current controllers are corrected through the added voltage drop on the inductance. After recalculation to the abc coordinates and dividing the half voltage of the DC bus we have the modulation signal for the modulator of the active rectifier. The rectifier is four-level with flying capacitors, therefore the PWM modulator has to be able to ensure proper voltage control as well as balance the voltage of the flying capacitors. There are many kinds of the modulation techniques, such as PSPWM with active balancing, PD-PWM with active balancing or conventional vector modulation. The modulations with the triangular carried signals use always one carried signal on each transistor pair. The carried signals are shifted in the phase (PS-PWM phase shifted PWM) or in amplitude with different offset (PD-PWM - phase disposition), where the phase is the same for all carried signal. The balancing could be done through the balancing controllers, which corrects the modulation signal (especially PS-PWM) or by using the balancing look up table (especially PDPWM and vector modulations).[2]

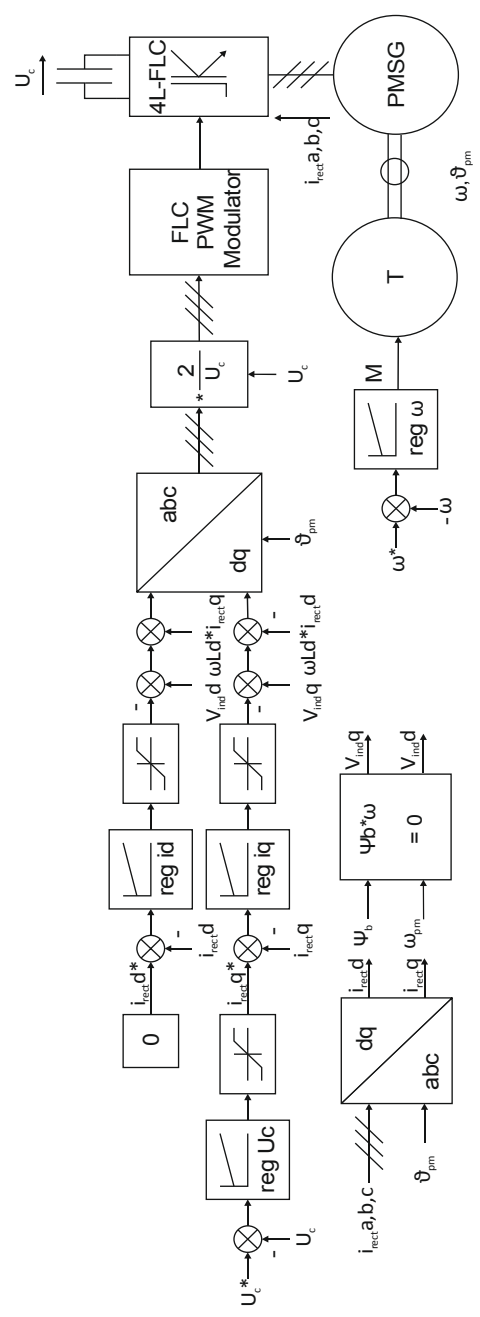

Figure 5 Control structure of the FLC rectifier

\section{VECTOR CONTROLLED INVERTER}

The control structure is shown on Figure 6.The current control structure is the same as with the case of inverter, but in inverse mode. In the grid mode the active power controller sets the demanded current in the $d$ axis and the reactive power controller sets the demanded current in the $q$ axis. The position of the grid voltage vector is obtained from arcustangens $(\mathrm{u} \beta / \mathrm{u} \alpha)$. After transition from grid mode to the island mode the control of the active-reactive power is replaced with the frequency-voltage control. In island mode, the position is generated by triangular generator with the requested frequency. The voltage controllers set the demanded current in the $d q$ coordinated system. After the refreshing of the grid voltage, the inverter in the island mode is able to adjust the same phase and amplitude as the grid voltage phase and switch back to the grid mode without voltage and current peaks. The synchronization could be solved through the phase locked loop (PLL) which is able to provide the position of the grid voltage vector without distortion which could appear there due to distortion of the grid voltage. [3], [4] 


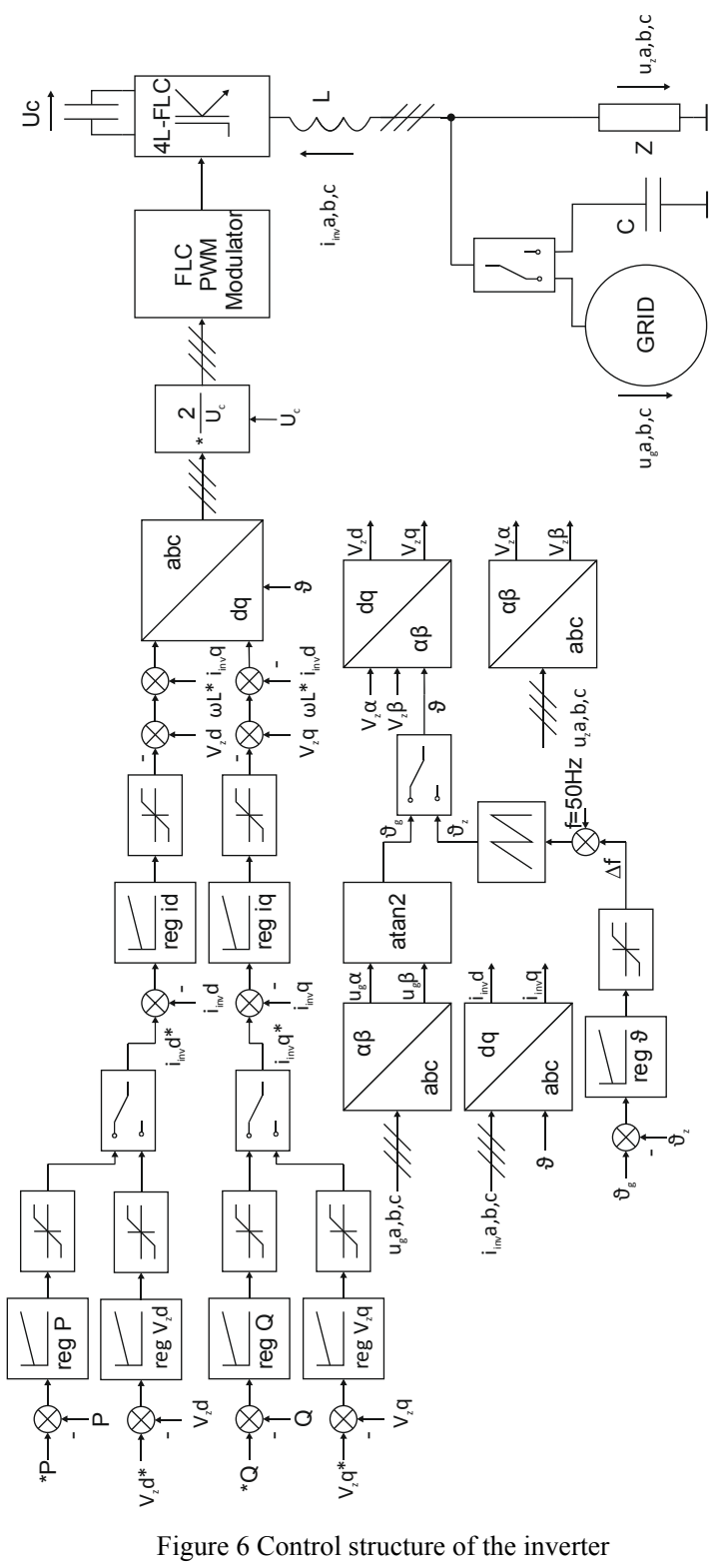

V. Simulation OF THE UPS SYSTEM

The next Figures show behavior of simulated UPS system with PMSG with FLC AC/DC/AC converter by transitions between grid and island mode (Figure 7, Figure 8, Figure 9).

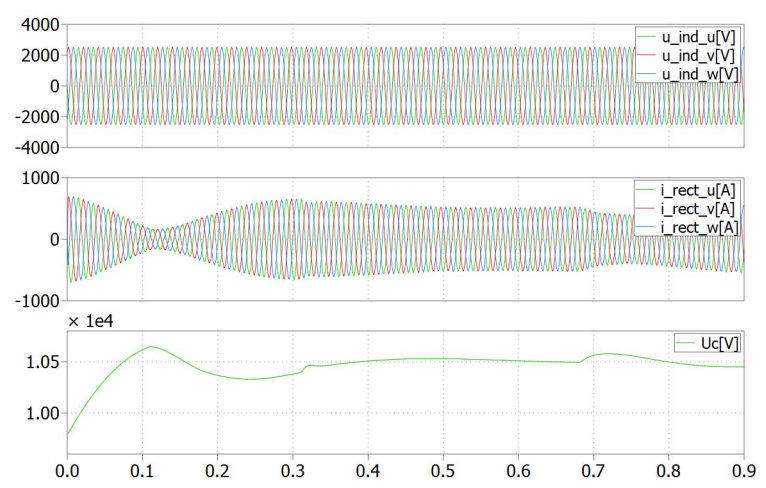

Figure 7 Induced voltage of PMSG [V], phase currents of PMSG [A], DC bus voltage [V]

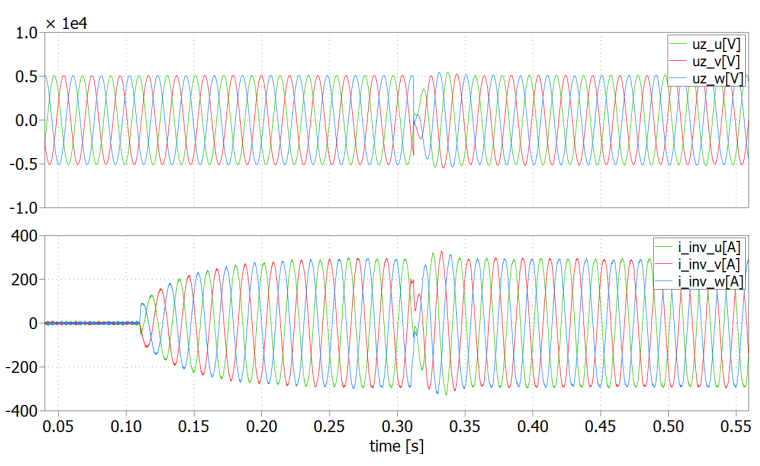

Figure 8 Grid voltage [V], currents of the convrter [A] and switch for transition from grid mode to island mode

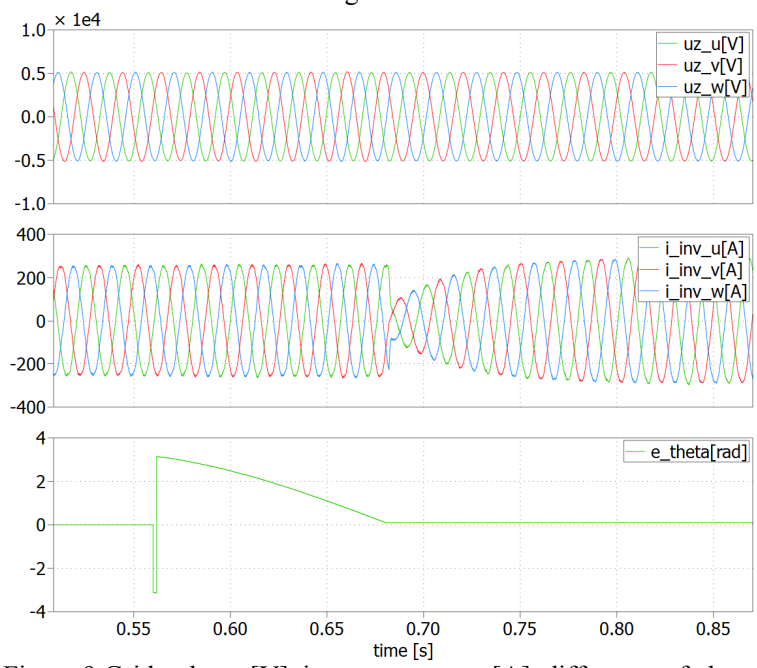

Figure 9 Grid voltage [V], inverter currents [A], difference of phase of the refreshed grid and phase of the inverter in island mode -

there is diplayed influence of the phase controller before the switching to the grid mode [rad], voltage of DC bus [V] and switch for the view of the request on the transition from island mode to the grid mode

\section{FLC PS-PWM MODULATOR WITH ACTIVE BALANCING}

The PS-PWM modulation has on each transistor pair one carried triangular carried signal which is compared with the input modulation signal. The active balancing is based on modification of the modulation signal by using controllers which causes the increase or decrease of the modulation index (Figure 10). That means that the modulation index is first modified through the balancing controllers and after multiplying the controller outputs with the input modulation signal we obtained the modified modulation signals which are connected to the input of the PS-PWM modulator. The outputs of the modulator are connected to the IGBTs through the dead-time generator. [6]

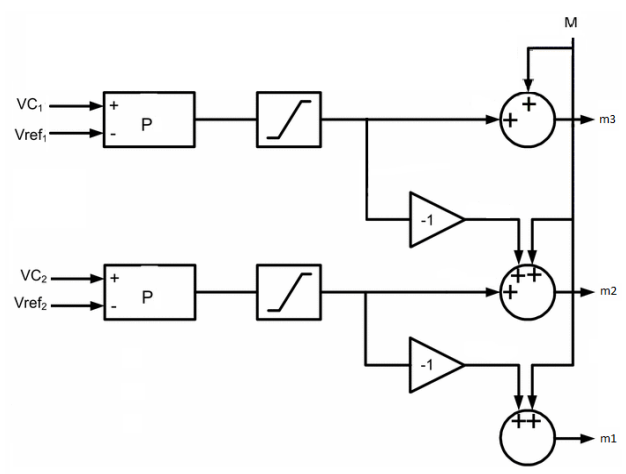

Figure 10 Balancing of flying capacitors control structure [6] 
The correct function was verified in the experiment with FLC AC/DC/AC converter. We have used a laboratory prototype with diode rectifier. Correct function of the FLC inverter with PS-PWM modulation with active balancing was tested with asynchronous machine as load. The hardware of control system is shown on Figure 11, the FLC AC/DC/AC converter on Figure 12. Measured results are in Figure 13 and Figure 14. [7]
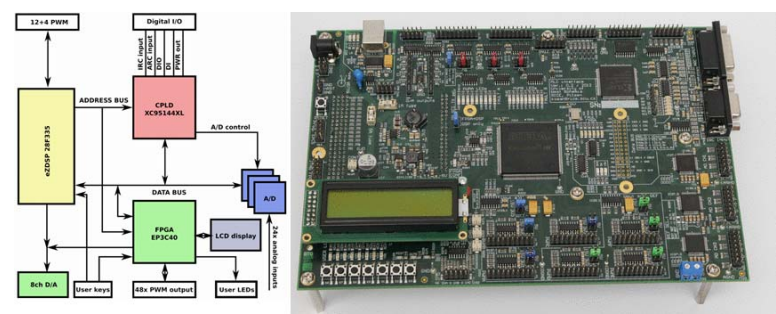

Figure 11 Block diagram and photo of the hardware MLC interface

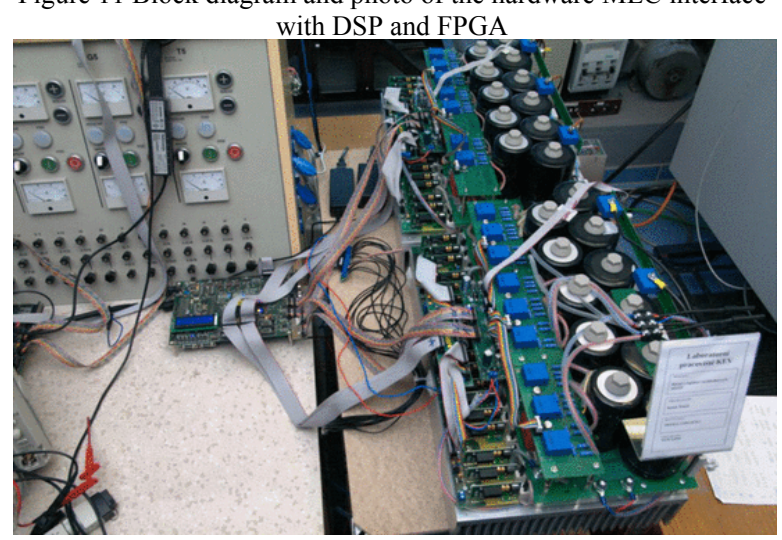

Figure 12 Photo of the FLC AC/DC/AC converter

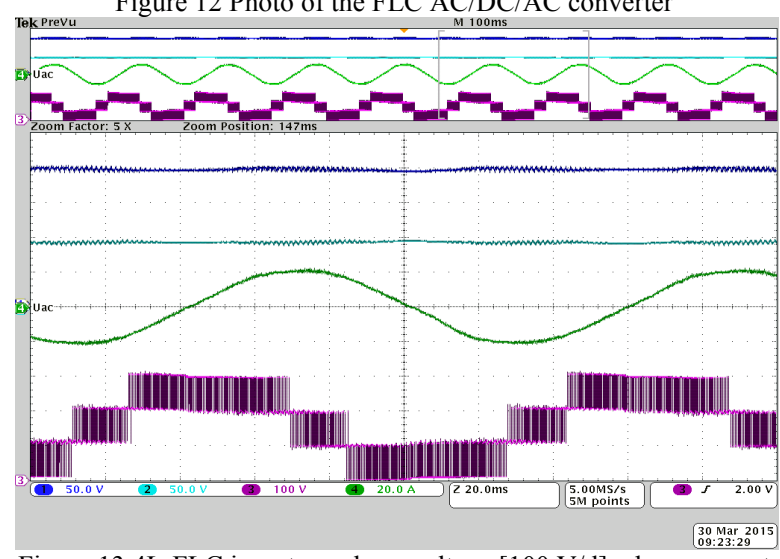

Figure 13 4L-FLC inverter - phase voltage [100 V/d], phase current $[20 \mathrm{~A} / \mathrm{d}]$ and FLC voltage $[50 \mathrm{~V} / \mathrm{d}]$, frequency $8,3 \mathrm{~Hz}$

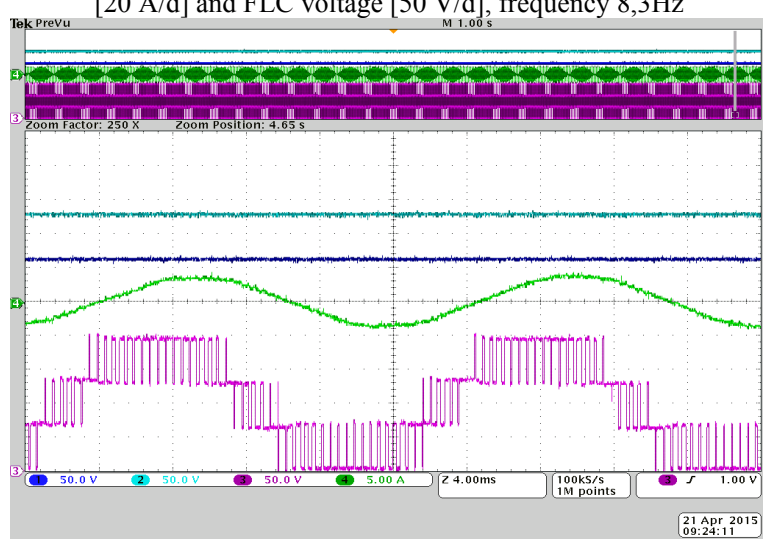

Figure 14 4L-FLC inverter - phase voltage [100 V/d], phase current $[20 \mathrm{~A} / \mathrm{d}]$ and FLC voltage $[50 \mathrm{~V} / \mathrm{d}]$, frequency $50 \mathrm{~Hz}$

\section{CONLUSIONS}

This paper describes the principals of the simulation of the UPS system with PMSG and FLC $\mathrm{AC} / \mathrm{DC} / \mathrm{AC}$ converter for high voltage applications and shows the results of the simulation of transitions between grid/island modes. It also describes in detail the FLC PS-PWM modulator with active balancing which was implemented to the FPGA. The correct function of the FLC modulator was verified by experimental measurement.

\section{ACKNOWLEDGMENT}

This research has been supported by the Ministry of Education, Youth and Sports of the Czech Republic under project No. LO1607: RICE - New Technologies and Concepts for Smart Industrial Systems. This research has been also supported by the project SGS2015-038.

\section{REFERENCES}

[1] Li-Xia Sun; Zhe Wang; Feng-Ling Han; Feng Yong, "A chattering-free terminal sliding mode control of direct-drive PMSG for wind generation system," Cyber Technology in Automation, Control, and Intelligent Systems (CYBER), IEEE 2014

[2] Janik, D.; Kosan, T.; Zeman, M.; Streit, L.; Peroutka, Z., "Active voltage balancing control with phase disposition PWM for 4-level flying capacitor converter," Power Electronics and Applications (EPE), IEEE 2013

[3] Areerak, K-N.; Bozhko, S.V.; Asher, G.M.; Thomas, D.W.P., "DQ-transformation approach for modelling and stability analysis of AC-DC power system with controlled PWM rectifier and constant power loads," Power Electronics and Motion Control Conference, 2008. EPE-PEMC, IEEE 2008

[4] Guo Li; Li Xialin; Zhou Qi; Liu Zhichao; Liu Shu; Shi Shan, "Control Strategies for a Hybrid PV/Battery System with Grid-Connected and Island Mode,APPEEC, IEEE 2012

[5] S. A. O. da Silva, P. F. Donoso-Garcia, P. C. Cortizo and P. F. Seixas, "A three-phase line-interactive UPS system implementation with series-parallel active power-line conditioning capabilities," inIEEE Transactions on Industry Applications", IEEE 2002.

[6] Khazraei, M., Sepahvand, H., Corzine, K., Ferdowsi, M., A generalized capacitor voltage balancing scheme for flying capacitor multilevel converters, IEEE 2010.

[7] J. Brychcín, D. Janík, T. Košan and Z. Peroutka, "Modulator for 4-level flying capacitor converter with active voltage balancing control with P controllers,"Electrical Drives and Power Electronics (EDPE)", IEEE 2015 